\title{
Residents' Perceptions on Study Tourism Impacts
}

\author{
Haiming Chen \\ Faculty of Tourism and Historical Culture \\ Zhaoqing University \\ Zhaoqing, China
}

\author{
Xudong Guo* \\ Faculty of Tourism and Historical Culture \\ Zhaoqing University \\ Zhaoqing, China \\ *Corresponding Author
}

\author{
Xuemei Mo \\ Faculty of Tourism and Historical Culture \\ Zhaoqing University \\ Zhaoqing, China
}

\begin{abstract}
The purpose of this paper is to explore residents' perceptions of study tourism impacts. It concerns the development direction of local tourism directly. This study presents the results of qualitative and quantitative survey among residing families of a small mountain community located in south China. The findings reveal that residents' perceptions on study tourism include social civilization advancement and economic promotion. Based on the analysis results of residents' perception, the author puts forward some suggestions on the sustainable development of study tourism.
\end{abstract}

Keywords—study tourism; tourism development impact; resident perception

\section{INTRODUCTION}

Qiaotou town, Huaiji County, Zhaoqing city of Guangdong province, is rich in tourism resources, especially represented by karst landform. The local government takes tourism as a key development of the economic industry, but it returns to depression after an ephemeral prosperity time. Therefore, it is necessary to reexplore the tourism development forms suitable for local resources.

Study tourism is one of the six elements of new tourism(Wu, 2015). It is an important form of tourism development in the new era. The study tourism has a significant effect on the youth to increase their knowledge and cultivate their sentiment(changhong \& Gongyu, 2017). As a new business form of tourism development, the study tourism can promote the transformation and upgrading and healthy development of local tourism industry structure, and is the product of the combination of tourism and education in the new era(Rui, 2017).

Qiaotou town, Huaiji county of Zhaoqing city is an important study tourism base because of its abundant karst geological and geomorphological resources and habitat resources of swiftlets. The attitude of the local residents and how to develop study tourism in the region is the main concern of this article.

\section{LITERATURE REVIEW}

\section{A. Study Tourism}

Based on the motivation and experience factors, $\mathrm{Li}$ Jinzao proposed a new six elements of tourism "Business, health, learning, leisure, affection, strange" (Wu, 2015). Among them, "learning" refers to the study tourism, including study tourism, scientific research, training, expansion training, photography, various summer camp winter camp and other activities.

Education circles believe that study tourism is an offcampus education activity that combines research learning and travel experience through collective travel and centralized accommodation. It is an innovative form connecting school education and off-campus education, an important content of education teaching and an effective way to educate people through comprehensive practice(Rui, 2017).Carrying out study tourism can guide students to adapt themselves to the society and promote the deep integration of book knowledge and life experience. It is beneficial to meet students' increasing demand for tourism, to cultivate students' consciousness of civilized tourism and cultivate their behavioral habits of civilized tourism.

\section{B. Tourism Development Impact}

Since 1960, many scholars have studied the attitudes and perceptions of residents in tourism destinations from the economic, social, cultural and environmental impacts of tourism development, and tried to use structural equation model to answer the question of which variables will ultimately affect the residents' satisfaction. Finally, a unified theory is formed, that is, tourism development impact theory. This theory holds that the impact of tourism development can be divided into three categories(Andereck, 2005; Ap \& Crompton, 1998; Butler, 1974; Mathieson \& Wall, 1982), The first is the economic impact, such as increasing employment opportunities and increasing local incomes. The second is the influence of social culture, such as the rerecognition of traditional crafts and festivals, communication 
and understanding between different cultures. Finally, environmental impacts, such as protecting the environment and resources, are valued.

\section{Residents' Perception of Attitudes}

Residents of tourism destinations have a major role in sustainable tourism development in their areas. Tourism has to be managed with the help and interest of all stakeholders in a given territory with a focus on local inhabitants(Mohammadi \& Khalifah, 2014). Residents of any host area may perceive tourism in a positive way because of its potential for job creation, income generation, and enhanced community infrastructure, as has been found in many host communities. Alternatively, the residents of host areas may perceive tourism in a negative way because of the socio-cultural and environmental costs, as has also been found in many host communities(Andriotis \& Vaughan, 2003). Therefore, the perception of residents' attitude is the directional indicator of the success of tourism development in one region. At the same time, residents' attitude perception is also rich in the direction and methods of tourism development.

\section{SAMPLES AND DATA}

This paper combines qualitative and quantitative methods. First, it investigates the development process and overall situation of the local industry in the form of field survey and interview. Second, the paper questionnaire survey was conducted face to face among local residents by means of quantitative survey.

Non-random sampling method was used to randomly visit villages and towns in the survey area and distribute questionnaires. In this survey, three communities including Qiaotou community, Jinglian community and Tianxin community were visited, as well as four administrative villages including Dongjiang village, Shanhe village, Wuxia village and Gangtou village, as well as two famous tourist sources of Xanadu and Yanyuan.

The researcher designed eight questions for the interview survey: What tourism resources does Qiaotou town have? Qiaotou town tourism development from when to start, how effective? When did the tourist industry flourish in Qiaotou town? What specific performance? How is the current tourism development of Qiaotou town? What problems exist in the current tourism development of Qiaotou town? What countermeasures and ideas does the Qiaotou town government have to develop tourism in the future? How about the tourist reception capacity and conditions in Qiaotou town? How do the residents of Qiaotou feel about the development of tourism?

In this paper, the questionnaire design was based on tourism development impact theory, researchers according to the relevant academic research results, that is the impact of tourism development is divided into three aspects: economic impact, social and cultural impact and environmental impact. There are 18 questions in design, the questionnaire adopts Likert5 scale measure, 1 represents "very disagree", 2 "disagree", 3 represents "no opinion", 4 "identity", 5 "very identity".

In the basic research work, the researchers interviewed 12 village and town cadres and 3 business owners. In the questionnaire survey, researchers visited 4 villages and distributed 479 copies of paper questionnaires to local residents, and 400 copies of effective questionnaires were returned, with an effective rate of $83.5 \%$. Through the statistical analysis of the questionnaire sample information, the basic information of the questionnaire survey sample is obtained as shown in "Table I".

TABLE I. Statistical TABLE OF SuRvey SAMPLE AtTRIBUtes

\begin{tabular}{|c|c|c|c|c|c|c|c|}
\hline \multicolumn{2}{|r|}{ Sample attribute } & \multirow{2}{*}{$\begin{array}{l}\text { Frequency } \\
205\end{array}$} & \multirow{2}{*}{$\begin{array}{c}\text { Percent } \\
51.3 \\
\end{array}$} & \multicolumn{2}{|c|}{ Sample attribute } & \multirow{2}{*}{$\begin{array}{l}\text { Frequency } \\
135\end{array}$} & \multirow{2}{*}{$\begin{array}{l}\text { Percent } \\
33.8\end{array}$} \\
\hline \multirow{2}{*}{ gender } & male & & & \multirow{3}{*}{ marriage } & unmarried & & \\
\hline & female & 164 & 41.0 & & married & 202 & 50.5 \\
\hline \multirow{6}{*}{ age } & Under 18 & 44 & 11.0 & & else & 2 & .5 \\
\hline & $19-29$ & 152 & 38.0 & \multirow[t]{13}{*}{ profession } & Food and beverage & 8 & 2.0 \\
\hline & $30-39$ & 88 & 22.0 & & Services & 29 & 7.3 \\
\hline & $40-49$ & 37 & 9.3 & & the self-employed & 63 & 15.8 \\
\hline & $50-59$ & 33 & 8.3 & & Worker & 36 & 9.0 \\
\hline & 60 and above & 13 & 3.3 & & civil servant & 24 & 6.0 \\
\hline \multirow{5}{*}{$\begin{array}{c}\text { education } \\
\text { level }\end{array}$} & Junior secondary and below & 143 & 35.8 & & teacher & 13 & 3.3 \\
\hline & senior high school & 127 & 31.8 & & hospitality & 9 & 2.3 \\
\hline & college & 23 & 5.8 & & tourism & 7 & 1.8 \\
\hline & undergraduate & 61 & 15.3 & & peasant & 120 & 30.0 \\
\hline & master's and above & 2 & 0.5 & & enterprise manager & 3 & .8 \\
\hline \multirow{4}{*}{ income } & $2000 \mathrm{CNY}$ and below & 163 & 40.8 & & merchant & 4 & 1.0 \\
\hline & $2001-3000 \mathrm{CNY}$ & 63 & 15.8 & & student & 71 & 17.8 \\
\hline & $3001-4000 \mathrm{CNY}$ & 44 & 11.0 & & doctor & 11 & 2.8 \\
\hline & more than $4001 \mathrm{CNY}$ & 41 & 10.3 & & & & \\
\hline
\end{tabular}

a. Data analysis from SPSS21.0 


\section{ANALYSIS AND RESULTS}

\section{A. Interview Data Analysis}

The researchers learned from interviews with 12 village and township cadres in Qiaotou town:

1) The region has rich tourism resources and a good tourism image: Through interviews and field surveys, the researchers found that Qiaotou town is located in the southwest of HuaiJi county, 46 kilometers away from the county city, just 200 kilometers away from the city of Zhaoqing city and Guangzhou city. The town has rich tourism resources, most of the karst landform, like a natural big miniature garden. In the territory of 70 thousand acres of green field, standing more than 360 stone peaks of thousands of positions and states, decorated with 170 holes with characteristics of the caves. In recent years, the tourism industry of Qiaotou town has become increasingly mature, and the developed scenic spots (scenic spots) such as Yanyan, Xanadu and Yanshan, are ideal tourist destinations for vacation and summer leisure. Among them, Yanyan scenic area is the most famous scenic spot in this region. It is the largest and the most fantastic karst cave among more than 170 caves around. As the swiftlets congregate in the caves, they are known as Yanyan, which is also known as the "Chinese Yandu". This is the only bird's nest producing area in the inland of China. It has become a green ecological scenic spot integrating landscape, exploration, sightseeing, leisure, vacation, entertainment and health maintenance. Besides, it has built a national climbing team training base and swiftlet research base, which is one of the best bases for research and tourism in south China.

2) Difficulties in the development of tourism industry in this region: According to interviews and field surveys, the development of tourism industry in Qiaotou town has experienced three stages of starting, developing and declining. Some prominent problems have been exposed in the current stage. The development of tourism in this town started at the beginning of this century. With the unique endowment of tourism resources, it attracted a large number of tourists to come for sightseeing. The local government and residents have been investing heavily in the construction of hotels, restaurants and other tourism enterprises. Around 2010, there were 11 hotels, over 900 beds, 9 catering enterprises and over 1,100 seats. However, with the limit of the service life of tourism facilities, Tourism facilities have become obsolete without further maintenance and renovation. After 2015, the tourism industry began to decline. By 2017, there were almost no groups of tourists coming for sightseeing. The tourism industry in this region was experiencing extreme depression, with the number of employment in the tourism industry declining, and the business of hotel and restaurant plummeted, and the business of hotels and restaurants remained closed. By the time the researchers entered the town, only two hotels and restaurants were available. The two business owners told the researchers: " The off-season time is very long, the enterprise operation cost is high, basically can maintain the profit and loss balance, cannot hire the employee, all is oneself and the family work personally. "

3) This town actively explores new approaches to develop tourism: Through interviews and field surveys, the researchers found four major problems in the town's tourism development: First, the early investment in tourism facilities is basically dilapidated, cannot meet the basic tourist reception; Second, the existing tourism products stay in the relatively traditional monotonous public tours; Third, the development degree of tourism resources is not enough. It fails to fully explore the geological and geomorphology of the region and rural tourism elements such as swiftlets. Fourth, the town tourism off season is too long, which causes great difficulties for the tourism business. The enthusiasm of local residents for tourism development is waning. In order to overcome these difficulties, the local government has been actively exploring new development channels to develop study tourism. As a new element and form of tourism development, study tourism can avoid the peak season of tourism and provide sufficient tourist in the off-season, So as to achieve tourism products upgrading and transformation of development mode.

\section{B. Questionnaire Data Analysis}

The researcher adopted SPSS21.0 and AMOS21.0 software to analyze the data of valid questionnaire results recovered. The detailed analysis method is as follows:

1) Reliability analysis of the questionnaire: The reliability of Cronbach's coefficient was analyzed to ensure the reliability and consistency of all questions in the questionnaire. The analysis results show that the scale of reliability of each dimension of the questionnaire in this survey is above 0.8. See "Table II" for details, indicating that the overall reliability of the questionnaire is very high. 
TABLE II. RELIABILITY ANALYSIS

\begin{tabular}{|c|c|c|c|}
\hline No. & dimension & Scale & Cronbach's Alpha \\
\hline 1 & \multirow{8}{*}{ social culture } & 1. Study tourism activities have improved the level of local civilization & \multirow{8}{*}{0.915} \\
\hline 2 & & 2. Study tourism activities have enriched the local spiritual civilization & \\
\hline 3 & & 3. Study tourism activities have enriched local cultural activities & \\
\hline 4 & & 4. Study tourism activities have brought a new atmosphere to the local area & \\
\hline 5 & & 5. Study tourism have broadened the horizon of local residents & \\
\hline 6 & & 6. Study tourism activities have promoted the exchange of local and foreign cultures & \\
\hline 7 & & 7. Study tourism activities have brought new ideas and trends & \\
\hline 8 & & 8. Study tourism activities have improved the cultural literacy of residents & \\
\hline 9 & \multirow{5}{*}{ environmental impact } & 9. Study tourism activities have promoted the local public service level & \multirow{5}{*}{0.855} \\
\hline 10 & & 10. Study tourism activities have promoted the infrastructure construction in this region & \\
\hline 11 & & 11.Study tourism activities have strengthened the awareness of local business services & \\
\hline 12 & & 12. Study tourism activities have promoted the image publicity of the region & \\
\hline 13 & & 13.Study tourism activities have improved the regional image of the region & \\
\hline 14 & \multirow{5}{*}{ economic impact } & 14. Study tourism activities have promoted economic consumption in the region & \multirow{5}{*}{0.905} \\
\hline 15 & & 15. Study tourism activities have driven the tourism consumption in this region & \\
\hline 16 & & 16. Study tourism activities have driven the region's food and beverage consumption & \\
\hline 17 & & 17. Study tourism activities have driven the accommodation consumption in the region & \\
\hline 18 & & 18. Study tourism activities have driven the region's traffic consumption & \\
\hline
\end{tabular}

2) Validity analysis and exploratory factor analysis: In this paper, factor analysis was used to verify the construction validity of the items in different dimensions of the questionnaire, and the KMO and Bartlett values of the variables of the questionnaire were detected, as shown in "Table III".

TABLE III. KMO AND BARTLETT TESTS

\begin{tabular}{|l|l|l|}
\hline \multicolumn{2}{|c|}{ Kaiser-Meyer-Olkin } & .939 \\
\hline \multirow{3}{*}{ Bartlett } & chi-square & 4206.101 \\
\cline { 2 - 3 } & df & 153 \\
\cline { 2 - 3 } & Sig. & .000 \\
\hline \multirow{2}{*}{ a. Data analysis from SPSS21.0 }
\end{tabular}

Two new dimensions were explored through exploratory factor analysis as "Table IV", and the optimal factor analysis results were obtained by deleting the items with both molecular values exceeding 0.4 and the common factor variance lower than 0.5 . The researchers interpreted the new factors, and found that the first dimension focuses on the promotion and improvement of social culture and management service level. According to the common direction, the researchers named the new dimension "social civilization advancement". The problems of the other dimension are very focused on driving tourism and economic consumption, so the researchers call this one dimension "economic promotion".

TABLE IV. FACTOR ANALYSIS ROTATION COMPONENT MATRIX

\begin{tabular}{|c|c|c|}
\hline \multirow{2}{*}{ title } & \multicolumn{2}{|c|}{ component } \\
\hline & 1 & 2 \\
\hline 3. Study tourism activities have enriched local cultural activities & .846 & .213 \\
\hline 2. Study tourism activities have enriched the local spiritual civilization & .837 & .091 \\
\hline 7. Study tourism activities have brought new ideas and trends & .808 & .258 \\
\hline 8. Study tourism activities have improved the cultural literacy of residents & .798 & .236 \\
\hline 1. Study tourism activities have improved the level of local civilization & .771 & .066 \\
\hline 6. Study tourism activities have promoted the exchange of local and foreign cultures & .743 & .263 \\
\hline 10. Study tourism activities have promoted the infrastructure construction in this region & .625 & .365 \\
\hline 16. Study tourism activities have driven the region's food and beverage consumption & .186 & .887 \\
\hline 17. Study tourism activities have driven the accommodation consumption in the region & .187 & .883 \\
\hline 15. Study tourism activities have driven the tourism consumption in this region & .296 & .845 \\
\hline 18. Study tourism activities have driven the region's traffic consumption & .150 & .838 \\
\hline
\end{tabular}

3) Confirmatory factor analysis: Based on the results of exploratory factor analysis, the researcher selected a total of 14 problems from the two aspects of social civilization advancement and economic promotion, draw the preestablished model diagram in AMOS21.0, The maximum
Data analysis from SPSS21.0 likelihood method is used for confirmatory factor analysis. After calculating the estimated value, the model can be identified with smooth convergence. After the model is modified, it is shown in "Fig. 1". 


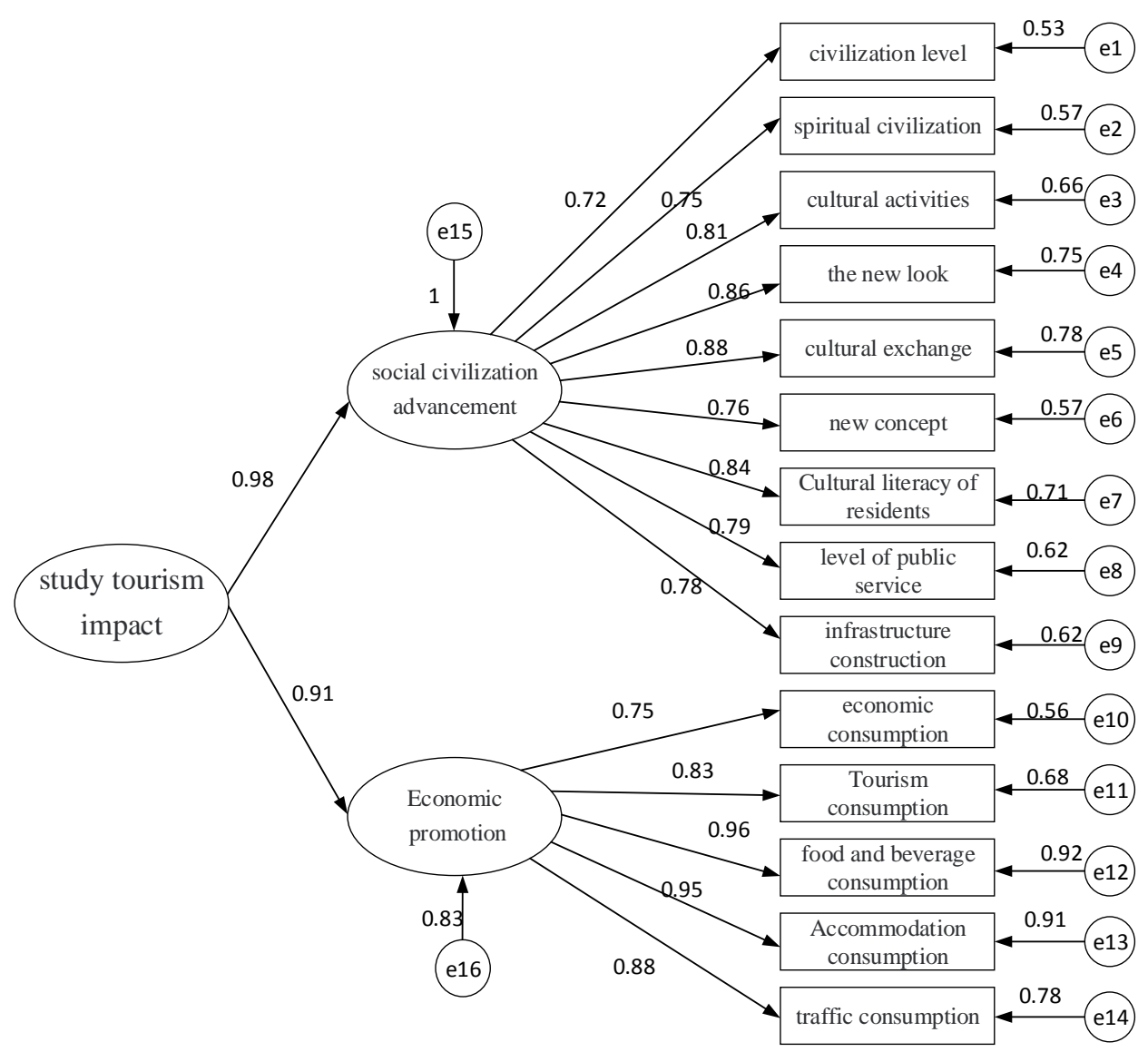

Fig. 1. Model diagram of the research on the impact of tourism development.

The data results obtained from the confirmatory factor analysis are shown in "Table V", As can be seen from the data in the table, all path relationships in the model are significant, The relation coefficient of each path is between 0.725 and 0.981 , and the coefficient value is relatively ideal.
Data from AMOS21.0 software analysis The load of each factor is between 0.526 and 0.922 , and the load of most factors is larger than 0.6, indicating that the dimensions of the new construction are explained by each factor in the model.

TABLE V. Summary TABle OF Model ANalysis Data

\begin{tabular}{|c|c|c|c|c|c|}
\hline \multicolumn{3}{|c|}{ Path relationship } & \multirow{2}{*}{$\begin{array}{c}\begin{array}{c}\text { Estimated path } \\
\text { coefficient }\end{array} \\
0.981 \\
\end{array}$} & \multirow{2}{*}{$\begin{array}{r}\begin{array}{r}\text { Load } \\
\text { factor }\end{array} \\
0.962 \\
\end{array}$} & \multirow[t]{2}{*}{$\begin{array}{c}\text { Path } \\
\text { significance }\end{array}$} \\
\hline social civilization advancement & <--- & study tourism impact & & & \\
\hline economic promotion & $\begin{array}{ll}<-- \\
\end{array}$ & study tourism impact & 0.909 & 0.826 & \\
\hline civilization level & $<--$ & social civilization advancement & 0.725 & 0.526 & \\
\hline spiritual civilization & $<---$ & social civilization advancement & 0.753 & 0.567 & $* * *$ \\
\hline cultural activities & <--- & social civilization advancement & 0.813 & 0.661 & $* * *$ \\
\hline the new look & <--- & social civilization advancement & 0.865 & 0.748 & $* * *$ \\
\hline cultural exchange & $\begin{array}{ll}<--- \\
\end{array}$ & social civilization advancement & 0.880 & 0.774 & $* * *$ \\
\hline new concept & $\begin{array}{ll}<-- \\
\end{array}$ & social civilization advancement & 0.756 & 0.572 & $* * *$ \\
\hline Cultural literacy of residents & $\begin{array}{ll}<-- \\
\end{array}$ & social civilization advancement & 0.843 & 0.711 & $* * *$ \\
\hline level of public service & $<--$ & social civilization advancement & 0.787 & 0.619 & $* * *$ \\
\hline infrastructure construction & <--- & social civilization advancement & 0.785 & 0.616 & $* * *$ \\
\hline economic consumption & $<---$ & economic promotion & 0.749 & 0.561 & \\
\hline Tourism consumption & $<---$ & economic promotion & 0.827 & 0.684 & $* * *$ \\
\hline food and beverage consumption & <--- & economic promotion & 0.960 & 0.922 & $* * *$ \\
\hline Accommodation consumption & $\begin{array}{ll}<--- \\
\end{array}$ & economic promotion & 0.955 & 0.912 & $* * *$ \\
\hline traffic consumption & <--- & economic promotion & 0.882 & 0.778 & $* * *$ \\
\hline
\end{tabular}


The relationship coefficients of the two paths established in the model are all greater than 0.909, and the regression effect is relatively ideal. Among them, the coefficient of regression relation between "social civilization promotion" and "study tourism impact" is larger, which indicates that study tourism has greater influence on the construction of social civilization degree. Among the 14 single factors in the model, the largest factor loading was "food and beverage consumption" and "accommodation consumption", both above the ideal level of 0.9 ; the smallest factor load is "civilization level", because "civilization level" is a relatively comprehensive development index, which requires the common development of all industries, including tourism development.

\section{CONCLUSION}

\section{A. Discussion}

1) QiaoTou town has good conditions and foundation for the development of research tourism: Interviews, surveys and field surveys reveal that Qiaotou town is rich in geographical and biological tourism resources, which have good education and research value, and have a good reputation for resources within the province, which is very suitable for the development of study tourism. At the same time, the investigation found that Qiaotou town has more than ten years of tourism development history and rich experience in tourism economic development. These can provide effective reference for the development of study tourism.

2) Study tourism will effectively promote the social civilization and the economic development of QiaoTou town: According to the data analyzed by the exploratory factor analysis method, the path coefficients of "social civilization promotion" and "economic promotion" are both greater than 0.9, It shows that the study tourism development in Qiaotou town can effectively promote "social civilization" in the town and effectively promote the economic development.

3) Study tourism will directly drive the overall development of tourism in QiaoTou town: In this paper, the validation factor analysis of 14 single factors explored in exploratory factor analysis found that the largest factor loading was "food and beverage consumption" and "accommodation consumption". Both of the two factors are above the ideal level of 0.9 , which indicates that among the residents' perceived influences on the development of study tourism, the biggest and most direct driving force is the catering and hotel accommodation industry.

\section{B. Suggestion}

According to the research results, the researchers put forward the following strategy for developing new tourism elements and promoting the tourism industry transformation and upgrading in Qiaotou town.
1) Make use of the advantages of geography and biological resources to build a research tourism base: Qiaotou town is rich in karst geological features and unique swiftlet biological resources, that has better education function and higher education value, so Qiaotou town can promote the construction of large public facilities, and can actively cooperate with well-known colleges and universities, industrial and mining enterprises, scientific research institutions, explore and build a comprehensive research practice base, strive to build a demonstration travel routes.

2) Make great efforts to plan and design study tourism products and transform the development mode of tourism: As a key element of tourism development in the new era, study tourism can promote the construction of beautiful villages. Qiaotou town should highlight the beautiful scenery of the motherland on the basis of base construction. According to the study tourism objectives of students in primary, middle and high schools, develop various types of activity courses, such as nature, geography, humanities and experience.

3) Mobilize the town residents to actively participate in the anti-season development of the tourism industry: The long off-season of traditional tourism makes it difficult for local tourism reception enterprises to continue, and they withdraw from the market in succession, which makes the development of tourism industry backward. Qiaotou town should make full use of the opportunity of the development of study tourism, mobilize the original tourism reception enterprises of the town to update the reception facilities, and actively participate in the construction of study tourism, promote the anti-seasonal development of related industries in various fields, and create a more sustainable development model of tourism industry.

\section{Research Limitations}

During the process of this study, the factors limiting research progress include three aspects: First, the research work of this study coincided with the busy summer agricultural season. When researchers conducted research by visiting households, local villagers were busy with farming and harvesting, making the research work slow and inefficient. Secondly, because Qiaotou town is located in a remote area, many respondents can't read, which made the questionnaire survey more difficult to some extent and affected the quality of the questionnaire. Third, in the research process, the interviewees cannot fully understand the new business mode of study tourism, which required the researchers to explain, and influenced the direct judgment of the interviewees. To some extent, these limitations may cause some errors to the research results, but that just make this study full of authenticity and significance. 


\section{REFERENCES}

[1] Andereck, K., Valentine,K M.,Knopf, R.C.\&Vogt, C.A. (2005). Resident perceptions of community tourism impacts Annals of Tourism Research, 32(4), 1056-1078.

[2] Andriotis, K., \& Vaughan, R. D. (2003). Urban Residents' Attitudes toward Tourism Development: The Case of Crete. Journal of Travel Research, 42(2), 172-185.

[3] Ap, J., \& Crompton, J. L. (1998). Developing and Testing a Tourism Impact Scale. Journal of Travel Research, 37(2), 120-130.

[4] Butler, R. W. (1974). The Social Implication of Tourism Development. Annals of Tourism Research, 2(2), 100-111.

[5] changhong, B., \& Gongyu, W. (2017). Take advantage of the value of action to study tourism. Journal of nankai University (philosophy and social sciences)(1), 151-159.

[6] Mathieson, A., \& Wall, G. (1982). Tourism, economic, physical and social impacts: Longman.

[7] Mohammadi, M., \& Khalifah, Z. (2014). Residents' attitudes and support for tourism development. Tourismos.

[8] Rui, D. (2017). Chongqing: the practice and exploration of the development system of study tourism. Education Today(5), 12-13.

[9] Wu, B.-H. (2015). How many elements does travel have? Global human geography(10), 10-10. 